\title{
Field study on heat pump monitoring: challenges and opportunities
}

\author{
Iole Nardi ${ }^{1,}{ }^{*}$, Carmen Lavinia ${ }^{1}$, Domenico Iatauro $^{1}$ and Nicolandrea Calabrese ${ }^{1}$ \\ ${ }^{1}$ ENEA (Italian National Agency for New Technologies, Energy and Sustainable Economic \\ Development), DUEE Dept., 00123 via Anguillarese 301 Santa Maria di Galeria (Rome), Italy
}

\begin{abstract}
In view of the decarbonisation targets in the building sector, heat pump can play a key role, marking the shift towards all-electric buildings. Although the heat pump technology is well known, and its use is ever increasing, some issues (practical and operative) are still open in the assessment of the main aspects that influence the efficiency. These complexities emerge when heat pump monitoring is carried out, allowing to assess the real performance. Therefore, in this work, the challenges and opportunities of heat pump monitoring are presented, from a field study of the tertiary sector. The monitoring of an air-to-water heat pump allowed to: (i) assess its real operating performance; (ii) compare the correlations of results with climate data and load profile; (iii) highlight some critical points, as the importance of data mining and data cleaning phase for the reliability of the results; (iv) assess and identify which is the temporal scale needed for a proper data elaboration.
\end{abstract}

\section{Introduction}

The EU aims to be climate-neutral by 2050, and strategic priorities have been defined for the goal: increase the carbon capture and storage; create carbon sinks; enhance the circular economy in the industrial sector; developing smart networks; clean mobility; energy efficiency; decarbonised energy supply [1]. Currently, the efforts for emissions reduction target for 2020 are paying off, and to achieve the current 2030 climate and energy targets each Member State has prepared integrated national energy and climate plans [2].

Also, the building sector can give its important contribution through a variety of interventions: increasing the use of renewable sources, improving the building envelope thermal characteristics (as, for instance, with insulation addition or by replacing the windows with more-efficient ones, by using solar shield), replacing the HVAC systems with fossil fuels-free ones.

In the wake of the latter solution, heat pump technologies can play a key role, and they are experiencing a growing market in North America, Europe, and Northern Asia [3].

Although being the most common adopted technology in newly built houses of many Countries, to date heat pumps supply only $5 \%$ of global building heating demand [4], but their share will hopefully quadruple by 2030 under the Sustainable Development Scenario

\footnotetext{
${ }^{*}$ Corresponding author: iole.nardi@enea.it
} 
(SDS). Indeed, it has been estimated that in 2030 heat pumps will account for $22 \%$ of the share of households purchasing for heating and hot water production in selected regions the Sustainable Development Scenario [3]), but support policies will help to reduce purchase and installation costs, by also removing market barriers [4].

Hence, heat pumps stay between the energy renovation wave, and the scepticism towards their real efficiency. Indeed, some issues (practical and operative) are still open in the assessment of the main efficiency-influencing aspects [5-9].

In this study, the analysis of air-to-water heat pumps behaviour, linked to climate conditions and load factor, has highlighted a real-operating efficiency.

Therefore, in this work, the challenges and opportunities of heat pump monitoring are presented. Evidences from field study are described, by referring to a case study belonging to the tertiary sector.

The monitoring allowed to: (i) assess the real operating performance of the heat pump; (ii) compare the correlations of results with climate data and load profile; (iii) highlight some critical points, as the importance of data mining and data cleaning phase for the reliability of results; (iv) assess and identify which is the temporal scale needed for a proper data elaboration.

\section{Preliminary considerations on heat pump monitoring}

When carriyng out a monitoring campaign of a heat pump, it is worth considering that data analysis (from acquisition to post-process) could not be so ordinary. Some inconveniences might arise in-situ, like:

-Wrong positioning of measuring equipment and instruments;

-Missing link between measuring and logging system;

-Instrument damage or breakage during their use;

-Wrong data setting;

-Unsaved data, due to disruption;

-Missing data, due to HVAC system turn off for maintenance;

-Outliers.

Add to this the issue related to instrument syncronization (when not connected to the same data logger), and to the possibility that some loggers (to which some instruments might be connected) take into account the winter time whilst other might not. These aspects, although being trivial, can cause measurement temporal shifts that emerge when data are post-processed and after an accurate check and data cleaning, needed to observe possible missing data.

A further issue is related to the best timestep for data acquisition : the shorter the timestep, the higher the number of data to be post-processed, the better the dynamic quantites variation over time reconstruction. To the contrary, the longer the timestep, the shorter the post-processing phase, but the less accurate the reconstruction of phenomena dynamics.

It is hard, in this sense, to sketch a proper timestep, being also dependent on the final goal of the monitoring. Indeed, if the monitoring is carried out to check if the HVAC system is correctly working even when outdoor temperature is very low (disregarding the efficiency), a long timestep can be accepted.

If the aim of the monitoring is to assess the efficiency of the heat pump (like in this case study), and to correlate it to other parameters, a shorter timestep is needed.

Moreover, a keypoint is the proper time scale for aggregating data. In fact, when data are post-processed in a short time scale (as, quarter-hour), it is hard to retrieve the seasonal 
perfomance of the heat pump, but indeed it allows to retrieve the puntual functioning efficiency. In fact, in a quarter-hour interval, there might be variations of a quantity (like outdoor temperature), that do not immediately influence other quantities (like the flow temperature). Or, on the contrary, it might happen that, during a sunny but cold winter day, the solar gain on some facades is so high that the HVAC is turned on but the indoor setpoint is lowered. It is like having different characteristic times of both outdoor environmental condition (or internal set point) and of electric load or thermal production. These effects are correlated but, since they have different apprearing times, they should be properly evaluted.

\section{Case study}

To assess the real performances of a heat pump, its operative functioning should be measured during normal operation, where «normal» means during its turning on and off due to conditioning requirement, influenced by the set point and by the environmental conditions in the place where it is located. Hence, the final (operative) performance might differ from that of datasheet, but it is strictly dependant on factors which are not under the manufacturer's control.

For the purpose of this work, a case study (a bank office) has been selected, in the framework of a research activity lead thanks to the cooperation with Banco BPM (the third bank group in Italy for number of branches, accounting for about $8 \%$ of the total share [10]) and Tech4eff (a service company [11]). It is worth saying that, the bank sector is keeping growing attention to the energy renovation of its bulding and HVAC stock; moreover, due to the energy audit obligation, a clusterization pyramid has been recently proposed [12] by the Italian National Agency for New Technologies, Energy and Sustainable Economic Development (ENEA) with Abi Lab (Research and Innovation Center for Banks), through which identify the sites where consumption monitoring is needed.

The bank under study is located in Fiorenzuola D'Arda (North Italy), a small city characterized by 2559 Degree Days in the climatic zone E (according to the Italian law [13]). Details on the building and on the heat pump are provided in table 1 [14-15], whilst in Figure 1 the heating capacity and total power input are plotted for different water temperatures (ranging from $35^{\circ} \mathrm{C}$ to $65^{\circ} \mathrm{C}$ ).

The heat pump was already equiped with an acquisition system, which allowed to $\log$ and store, every 15 minutes, data on the following:

- $\quad$ electric energy $[\mathrm{kWh}]$ consumed from the installation of the monitoring system;

- thermal energy $[\mathrm{kWh}]$ produced from the installation of the monitoring system;

- Water flow temperature $\left[{ }^{\circ} \mathrm{C}\right]$;

- Water return temperature $\left[{ }^{\circ} \mathrm{C}\right]$;

- $\quad$ Outdoor temperature $\left[{ }^{\circ} \mathrm{C}\right]$.

In this work, results on one heating season (from 15th October 2019 to 15th April 2020) are proposed. 
Table 1. Details on the case study (left) and on its heat pump (right)
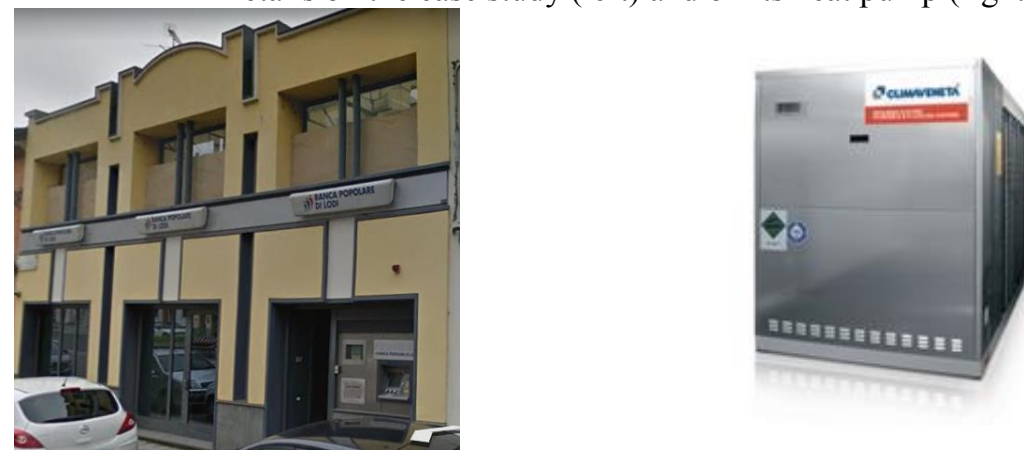

\begin{tabular}{|l|l|}
\hline Contruction Year: 1960 & Installation year: 2015 \\
\hline Building typology: beam and pillars & Heat pump typology: air-to-water \\
\hline Net heated surface: $240 \mathrm{~m}^{2}$ & Heating terminals: fan coil \\
\hline Gross heated surface: $306 \mathrm{~m}^{2}$ & $\begin{array}{l}\text { Product: Climaveneta } \\
\text { AWR HT LN CA-E } 0202\end{array}$ \\
\hline Volume: $855 \mathrm{~m}^{3}$ & Heating capacity: $69.6 \mathrm{~kW}$ \\
\hline & Total power input: $19.4 \mathrm{~kW}$ \\
\hline & COP: $3.55^{*}$ \\
\hline & DHW production: no \\
\hline
\end{tabular}

* In compliance with EN 14511-3:2011; plant side heat exchanger water (in/out) $40{ }^{\circ} \mathrm{C} / 45{ }^{\circ} \mathrm{C}$; source side heat exchanger air in $7{ }^{\circ} \mathrm{C}-87 \%$ R.H.

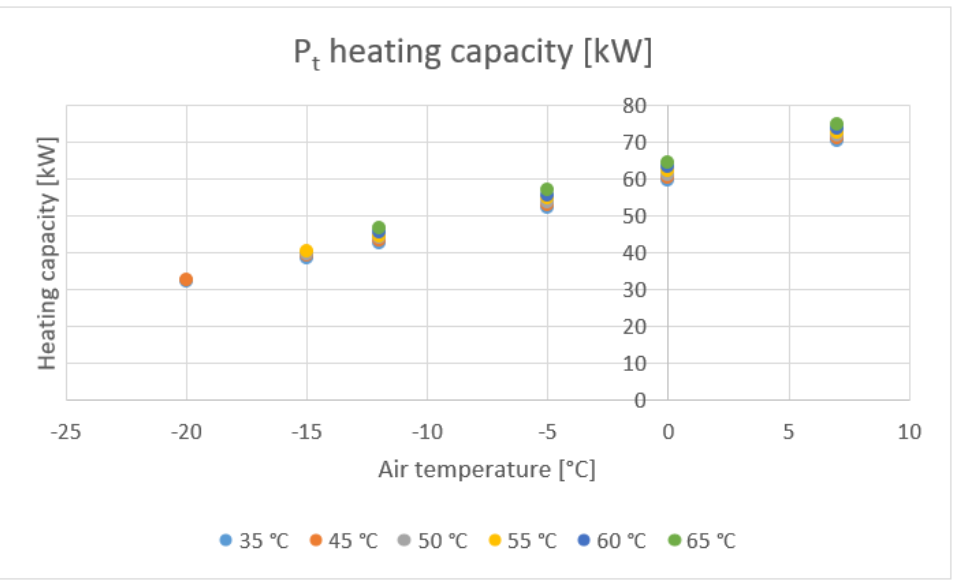




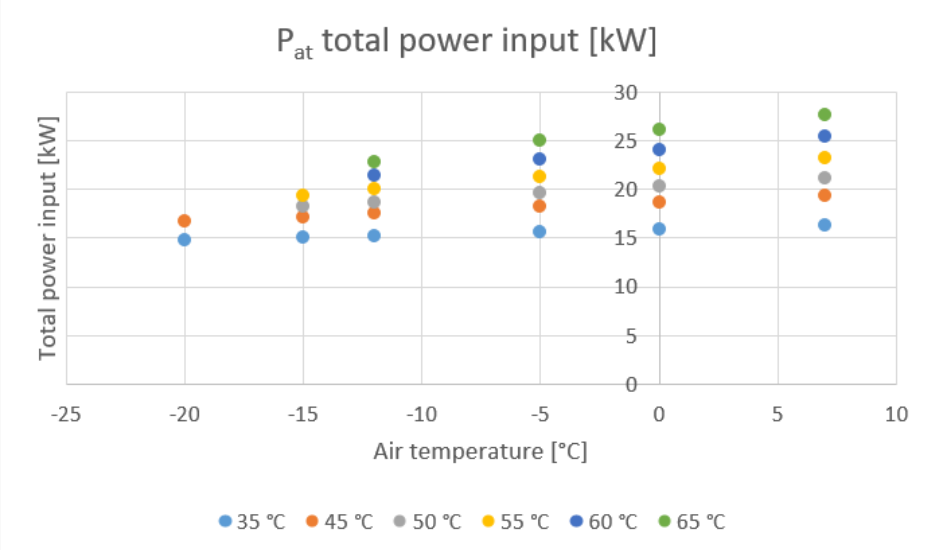

Fig. 1. Heat pump characteristics (from datasheet) [15].

\section{Methodology}

To work on data from the monitoring, which was already going on when the cooperation with Banco BPM and Tech4eff started, a methodology has been developed. The methodology has been defined after a series of data elaboration, attempts and considerations on raw data. Indeed, the work began with the rough ratio between thermal and electric energy recorded every 15 minutes, to retrieve a sort of instantaneous COP (coefficient of performance) which, of course, lacks of a strict correlation to the outdoor parameters and to the specific use of the HVAC plant. Therefore, a refinement (i.e. a proper data mining and data cleaning) was needed, to take into account the plant turning on and off, the working days and time, as well as specific conditions (on water temperature drop and on extreme COP) that allow to have data that can be correlated. Finally, the issue of the proper scale definition for results analysis was faced, since the interest for plant owners or manager could be on daily, weekly or seasonal scale.

The methodology definition has been a crucial point of this work, representing the way data should be processed. The series of attempts, graphs and considerations that lead to its definition are currently part of a research activity still on going within the Programme Agreement with the Italian Ministry of Economic Development, under the Electric System Research.

However, this delicate phase was necessary and mandatory, since literature on heat pump monitoring (which is not so plenty) lacks of the definition and explanation of a methodology or way to elaborate data. Indeed, as said in previous section, such elaboration cannot be given for granted, and it can deeply influence the final results (and considerations) on heat pump energy efficiency. This is the novelty of this work, which aims also to draw a line in the direction of thorough data processing.

The procedure (Fig. 2), developed for this case study (thus including references on the Italian law) entails the following phases:

- Acquired data must be in easily manageable file format, like *.csv, to allow elaboration through common systems, like spreadsheet or Matlab;

- Verify data consistency:

- Order of magnitude of acquired quantities;

- Absence of prolonged missing data (due to missing links, instruments breakage, wrong re-settings, etc);

- Data syncronization (or winter time onset); 
- Arrange the worksheet taking into account the information needed for the elaboration, by adding fields that allow to easily retrieve information on:

- Date and month of acquisition;

- Time;

- Weekday, weekends and holidays;

- Thermal (and electric) energy consumption, (both instantaneous and cumulative over the considered period);

- Water temperature drop;

- Data filtering, according to the following criteria :

- Divide data of the heating and of the cooling season. For the heating season, it is possible to refer to the lasting defined by the Italian law [14, 16] depending on the climatic zone where the HVAC is located ;

- Divide weekdays, weekends and holidays, and consider (in a precautionary way), holidays eves as full holidays ;

- Consider the plant working time from 8:00 to 18:00 (including extremes), thus considering not only the regular working time of the bank, but also the back office time and the timing for the clean up ;

- Exclude, from considerations, energy data which correspond to a water temperature drop (return-flow) lower than $2{ }^{\circ} \mathrm{C}$ (indeed, a temperature difference lower than $2{ }^{\circ} \mathrm{C}$ might be due to disruption or malfunctioning. Outdoor data, instead, are fully considered);

- Exclude data that, after the previous filter, have electric of thermal energy equal to zero: they might correspond to false acquisition ;

- Exclude data that, after the previous filter, have $\mathrm{COP}<2$ or $\mathrm{COP}>4$;

- Proceed with data analysis considering different time scales :

- Summing electric and thermal energy;

- Averaging (on the chosen time scale) temperature values ; 


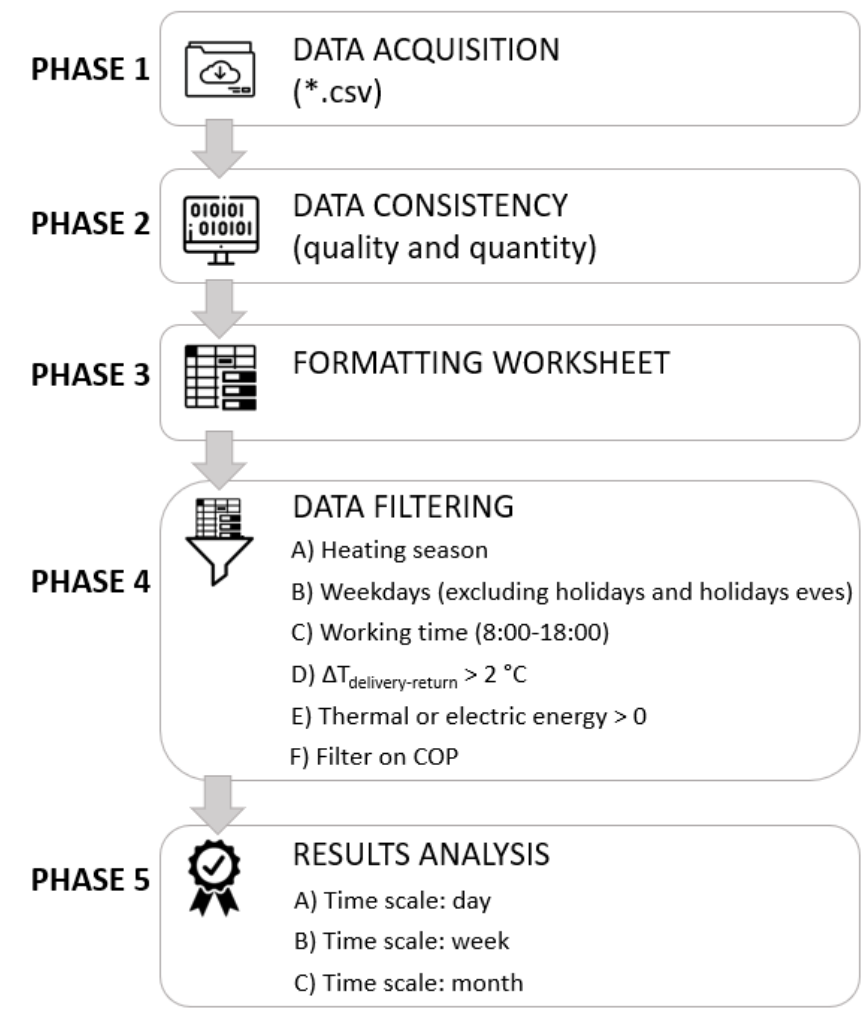

Fig. 2. Methodology flowchart.

It is evident that the original dataset, which counts over 17 thousand of data on quarterhour basis, will be reduced after the methodology to tens of data (on daily basis) (and even less on weekly basis).

This issue should be taken into account when defining a monitoring campaign. Indeed, as previously stated, having data with a close timestep (minute or quarter-hour) allows to recontruct phenomena which vary rapidily (those where the variation of a quantity causes a rapid variation on others). These phenomena, however, are not so common in air-to-water systems, whose thermal inertia (which is linked to the HVAC management system, to the water volume, to the number, typology and layout of terminal elements) causes a time lag between the electric energy consumed (needed for the heat pump functioning) and the rise in water temperature to the final elements.

Add to this a consideration on metrological characteristics of measuring devices, linked to their capability of "following " the quantity variation and to log the corresponding values. This implies that also the characteristic times of measuring devices should be taken into account according to the quantities (and expected quantity variation speed) to be measured.

Just think about the capability of turbine water flow meter to give precise values: in this kind of device, indeed, to a certain number of propeller rotation corresponds a determined water volume flown. But, if the number of rotations is less than those needed for the counter, the electric impulse is not sent to the logging system. This, in turn, implies that water has flown without being accounted (and thus measured). This entails having unprecise and «batch» measurements; therefore, enlarging the time scale could be 
convenient, instead of having a larger timestep for data acquisition, for better describing these phenomena.

\section{Results}

Data from the monitoring have been processed according to the explained methodology. COP values, shown in the following, cannot be paired nor roughly compared to the declared one, since the conditions under which results are now proposed differ from lab testing (which refer to controlled conditions). In the following, results are plotted taking into account that the aim of the monitoring was to assess the performances according to different time scale.

On daily basis, after the data filtering described in the methodology, the dataset is reduced to 50 points. The performance of the heat pump, on daily scale, confirms the expectations: COP increases when the outdoor temperature increases (Fig. 3).

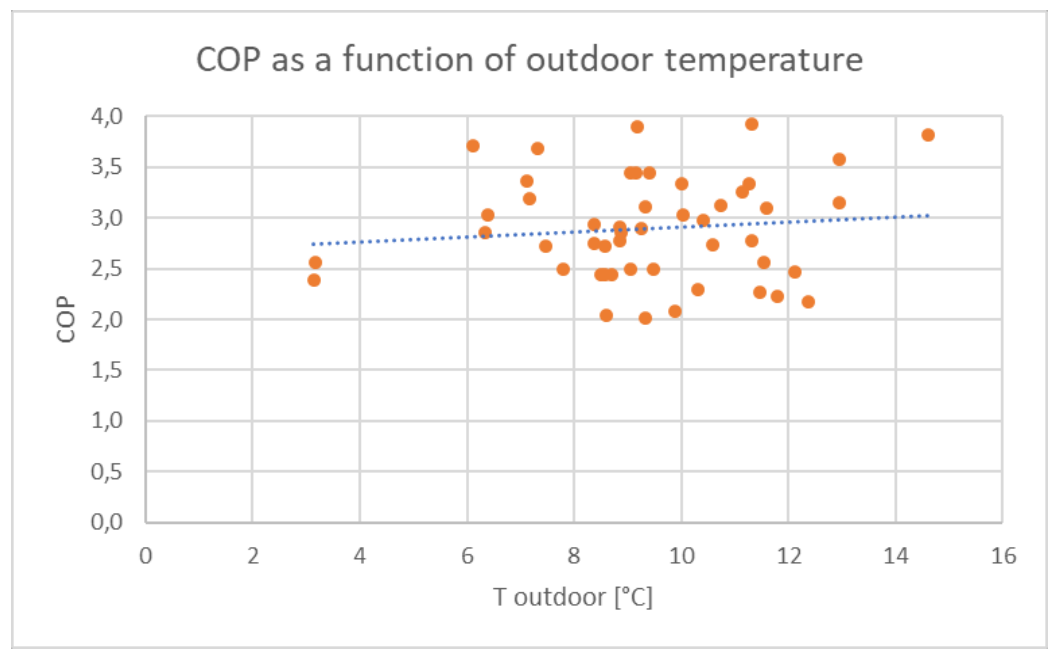

Fig. 3. COP as a function of outdoor temperature (on daily scale)

However, the COP shows a span variability (at given outdoor temperatures), suggesting that other factors have caused its ranging.

Surprisingly, the water temperature drop between flow and return was not fixed, (as proven by the point cloud of Fig. 4), but the COP seems not to be directly correlated to it. 


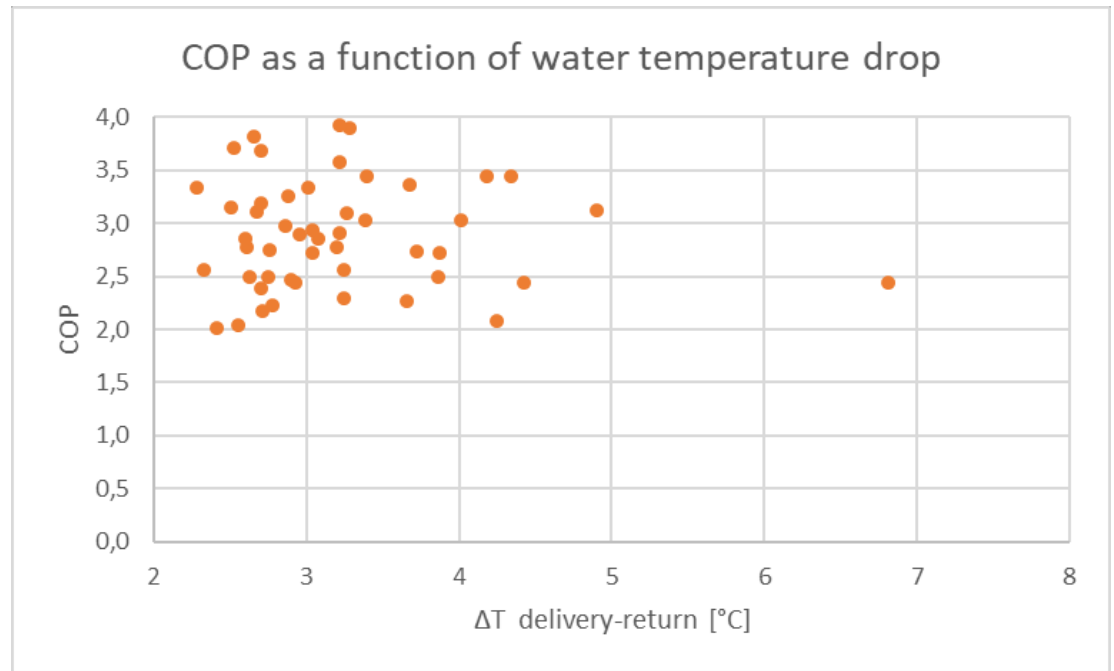

Fig. 4. COP as a function of water temperature drop (flow minus return) (on daily scale).

Indeed, the load factor (evaluated as the ratio between the electrical power and the total power input - from datasheet), clearly shows in Fig. 5 a decreasing trend when the outdoor temperature increases. This graph confirms the quality of the final dataset employed for the considerations.

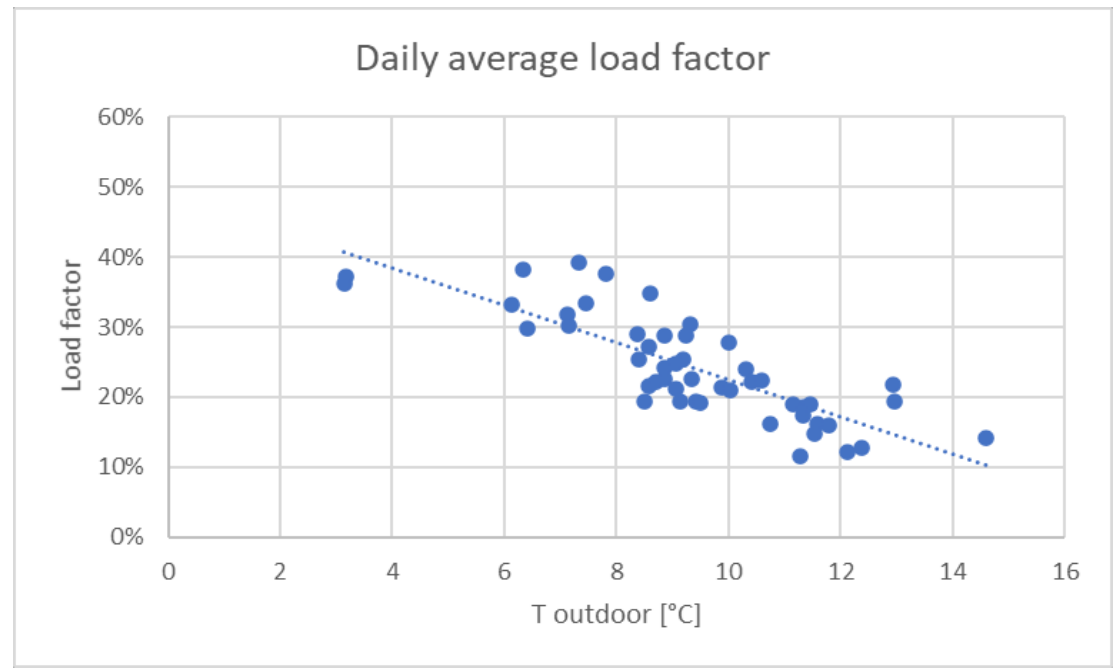

Fig. 5. Load factor as a function of outdoor temperature (on daily scale).

When a wider time scale is used, like the weekly one, the COP over the outdoor temperature is as per Fig. 6, where it is not so easy to identify a proper trend. Indeed, the temperature is averaged on a weekly basis (still considering the filters adopted in the methodology), but it does not influence in a relevant way the COP as it would on daily basis. This implies that the weekly basis does not easily allow to obtain considerations on the heat pump efficiency. 


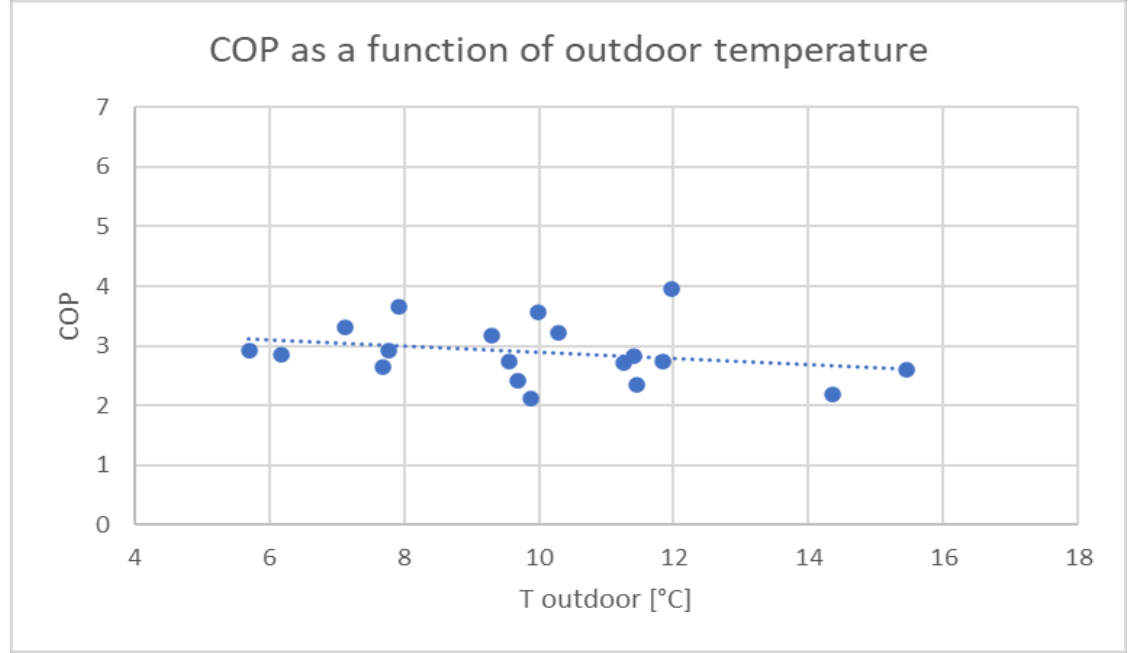

Fig. 6. COP as a function of outdoor temperature (on weekly scale).

Finally, a monthly basis has been employed (Fig. 7). Solid bars refer to the monthly data (without the data filtering described in the methodology), whilst hatched bars refer to the sum of data of electric and thermal energy by excluding the heat pump turning off (holidays, weekend and night) (their ratio provides the COP in green diamonds on Fig. 7).

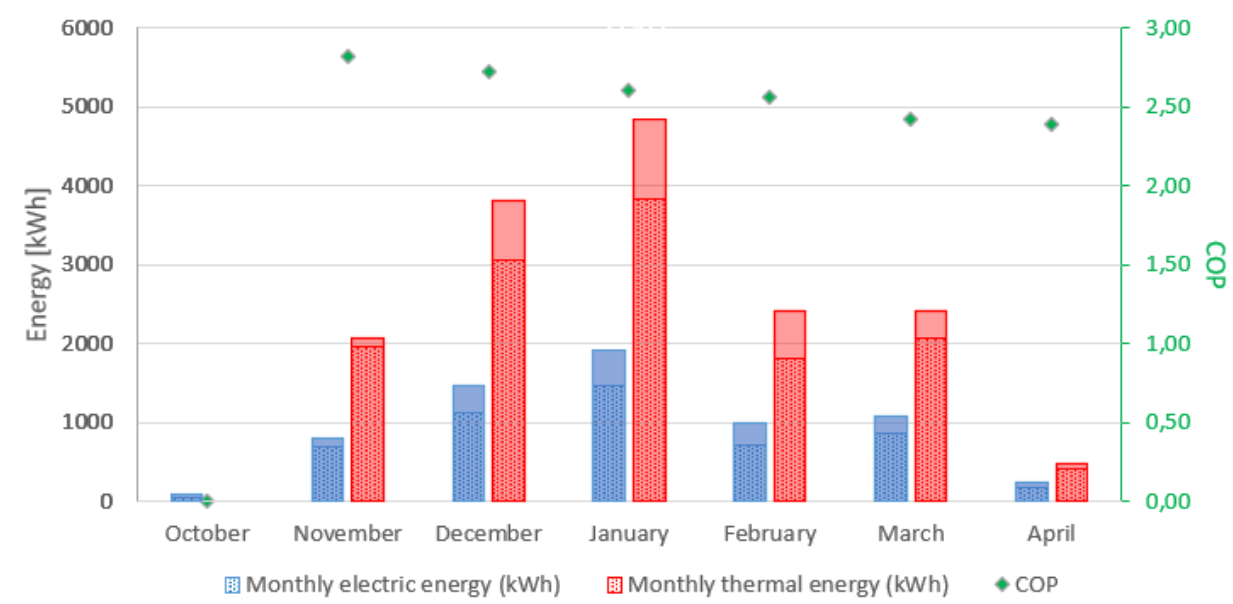

Fig. 7. Electric and thermal energy and COP (on monthly basis).

From this graph, it is possible to state that the intermediate months (October and April) do not have relevant loads, whilst December and January have the highest consumption. (in January a share of $29 \%$ of electric energy is consumed).

November and December have the highest COP (2.81 and 2.72, respectively). On a seasonal basis, considering the whole heating period, the average COP has been 2.42. This datum, as well as all COP provided, cannot be compared to that of Table 1, which is retrieved under specific conditions. 


\section{Final remarks}

The monitoring of a heat pump, although requires standard measuring devices commercially available, is not a trivial matter.

Many aspects, related to the campaign start up and follow up, to the measuring equipment characteristics and installation, to the aims of the monitoring itself, should be considering before installing the equipment and, in general, during data processing. This requires a purposely defined methodology, which takes into account all these issue and that can be drawn after a series of attempts and by experience.

In this sense, the heat pump monitoring provides challenges and opportunities, which are not so highlighted in the current literature, where, moreover, monitoring experiences are not so many.

In the following, those challenges and opportunities are listed, deriving from the direct experience of the monitoring of an air-to-water heat pump, serving a bank office.

-It is important to privilege the quality of the original dataset, instead of its abundancy, according to the heating or cooling seasons. This implies that a short timestep between two acquisition is not so relevant. In this case, indeed, the huge quantity of data to be post-processed might complicate (in terms of difficulty and computational time) the post-processing phase. On the contrary, it is important to have reliable data, being consistent in terms of coherence, without missing data, outlier or prolonged breaks ;

-Although being initially conspicuous, analyzable data can be reduced due to issues that often arise during in-situ measurements (wrong sensors positioning, settings, etc) ;

-When possible, it is adviceable to have surveys to periodically verify the correct positioning and functioning of the measuring equipment ;

-When drawing up a monitoring campaign, it is worth considering :

- Characteristic time for causes variation and effects display ;

- Characteristic time of measuring devices. This is quite relevant to properly $\log$ and store quantities.

-The quality of the final results strongly depends on the hypothesis made. In this sense, it is recommended to filter data (even with selective criteria) and to elaborate values having a physical meaning.

-The time scale, through which to post-process data, is important and allows to have different information on the heat pump efficiency or functioning. On this point, the literature does not provide sufficient background, so this research gap can be filled with further studies ;

-The hourly or sub-hourly scale, for instance, is good to represent the quantities variations over one or at least a few typical days, but it is not so useful to represent an overall heat pump efficiency ;

-A good compromise is given by the daily scale ;

- The shorter the temperature scale, the more dynamic are the working conditions ;

-The weekly scale helps to assess the overall quantities trend, but in some circumstances the monthly scale is appropriate ;

- To understand the seasonal variation, a monthly basis is needed.

The future research activities will include the set up of a generalized methodology, that starting from a decision tree allows to identify which could be the proper filters to apply to a dataset according to the aim of the monitoring. 


\section{Funding}

This research was funded by Programme Agreement with the Italian Ministry of Economic Development, under the Electric System Research.

\section{References}

1. https://ec.europa.eu/clima/sites/default/files/docs/pages/vision_1_emissions_en.pdf (last access: 16/06/2021)]

2. https://ec.europa.eu/clima/policies/strategies/progress_en

3. IEA, Share of households purchasing heat pumps for heating and hot water production in selected regions the Sustainable Development Scenario, 2010-2030, IEA, Paris https://www.iea.org/data-and-statistics/charts/share-of-households-purchasing-heatpumps-for-heating-and-hot-water-production-in-selected-regions-the-sustainabledevelopment-scenario-2010-2030

4. https://www.iea.org/reports/tracking-buildings-2020/heat-pumps\#abstract

5. G.L. Morrison, T. Anderson, M. Behnia, Sol Energ, 76 (2004) 147-152

6. K.J. Chua, S.K. Chou, W.M. Yang. Appl Energ 87 (2010) 3611-3624

7. B. Stojanovic', J. Akander. Appl Therm Eng 30 (2010) 188-195

8. K. Gram-Hanssen, T. Haunstrup Christensenb, P. E. Petersen. Energ Build 53 (2012) 64-73

9. O. Ruhnaul, L. Hirth, A. Praktiknjo. Sci Data 6 (2019) 189

10. https://www.tuttitalia.it/banche/ (last access: 14/04/2021)

11. http://www.tech4eff.com/

12. Diagnosi Energetiche art .8 del D.Lgs. 102/2014. Linee Guida e Manuale Operativo. Clusterizzazione, il rapporto di diagnosi ed il piano di monitoraggio, ENEA, Dipartimento Unità Efficienza Energetica, Laboratorio Efficienza Energetica nei Settori Economici, maggio 2019 https://www.efficienzaenergetica.enea.it/component/jdownloads/?task=download.send $\& \mathrm{id}=\% 20170 \&$ catid $=41 \&$ Itemid $=101$ (last access: $14 / 04 / 2021$ )

13. Decreto del Presidente della Repubblica 26 agosto 1993, n. 412. Regolamento recante norme per la progettazione, l'installazione, l'esercizio e la manutenzione degli impianti termici degli edifici ai fini del contenimento dei consumi di energia, in attuazione dell'art. 4, comma 4, della legge 9 gennaio 1991, n. 10

14. https://www.melcohit.com/IT/Products/Product.aspx?IdSottofamiglia=1615

15. https://produkte.cta.ch/cust/includes/user/files/kaeltemaschine/technischerProspekt/Tec hnical_brochures_AWR_HT_0122_0302_EN.pdf

16. Decreto del Presidente della Repubblica 16 aprile 2013 , n. 74. 